OAK RIDGE

NATIONAL LABORATORY

\title{
Radiolytic Degradation of Urethane Foam Used for Encapsulation of Contaminated Components
}

March 2006

Prepared by

G. D. Del Cul

C. M. Simmons

A. S. Icenhour

D. Singh

Prepared for the

Bechtel Jacobs Company, LLC

Oak Ridge, TN

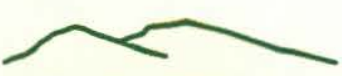

UT-BATTELLE 
This report was prepared as an account of work sponsored by an agency of the United States Government. Neither the United States government nor any agency thereof, nor any of their employees, makes any warranty, express or implied, or assumes any legal liability or responsibility for the accuracy, completeness, or usefulness of any information, apparatus, product, or process disclosed, or represents that its use would not infringe privately owned rights. Reference herein to any specific commercial product, process, or service by trade name, trademark, manufacturer, or otherwise, does not necessarily constitute or imply its endorsement, recommendation, or favoring by the United States Government or any agency thereof. The views and opinions of authors expressed herein do not necessarily state or reflect those of the United States Government or any agency thereof. 


\section{Radiolytic Degradation of Urethane Foam Used for Encapsulation of Contaminated Components}

\section{March 2006}

Prepared by

G. D. Del Cul

C. M. Simmons

A. S. Icenhour

D. Singh

Prepared for the Bechtel Jacobs Company, LLC

Oak Ridge, TN 
This report was prepared as an account of work sponsored by an agency of the United States Government. Neither the United States government nor any agency thereof, nor any of their employees, makes any warranty, express or implied, or assumes any legal liability or responsibility for the accuracy, completeness, or usefulness of any information, apparatus, product, or process disclosed, or represents that its use would not infringe privately owned rights. Reference herein to any specific commercial product, process, or service by trade name, trademark, manufacturer, or otherwise, does not necessarily constitute or imply its endorsement, recommendation, or favoring by the United States Government or any agency thereof. The views and opinions of authors expressed herein do not necessarily state or reflect those of the United States Government or any agency thereof. 
ORNL/TM-2006/15

Nuclear Science and Technology Division

\title{
RADIOLYTIC DEGRADATION OF URETHANE FOAM USED FOR ENCAPSULATION OF CONTAMINATED COMPONENTS
}

G. D. Del Cul

C. M. Simmons

A. S. Icenhour

D. Singh*

Date Published: March 2006

\author{
Prepared by \\ OAK RIDGE NATIONAL LABORATORY \\ P.O. Box 2008 \\ Oak Ridge, Tennessee 37831-6283 \\ managed by \\ UT-Battelle, LLC \\ for the \\ U.S. DEPARTMENT OF ENERGY \\ under contract DE-AC05-00OR22725
}

* Argonne National Laboratory 


\section{:}




\section{CONTENTS}

\section{Page}

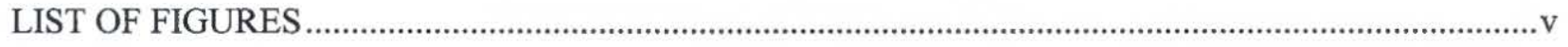

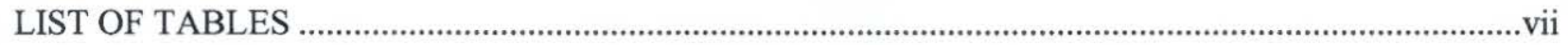

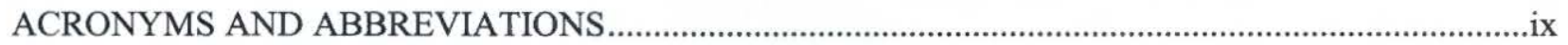

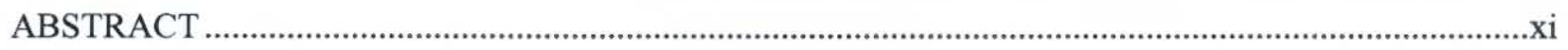

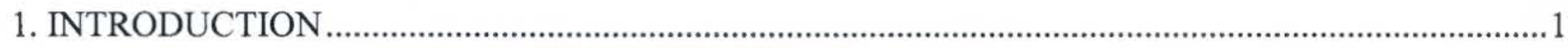

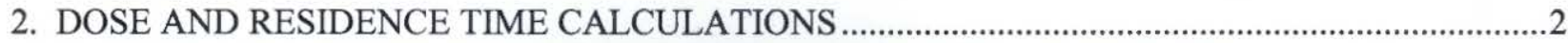

2.1 SUMMARY OF DOSE AND RESIDENCE TIME CALCULATIONS EQUIVALENT

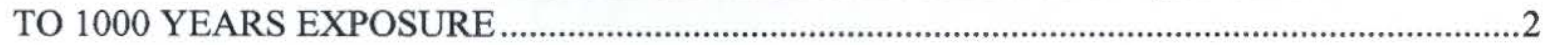

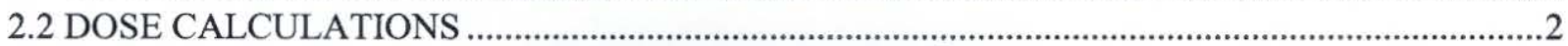

2.3 CALCULATION OF THE RESIDENCE TIME IN THE ${ }^{60}$ CO IRRADIATOR TO

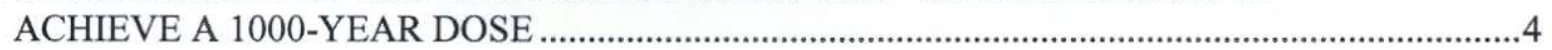

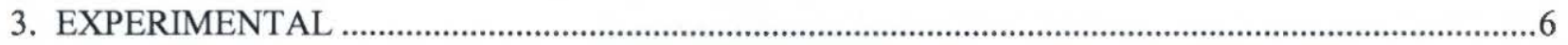

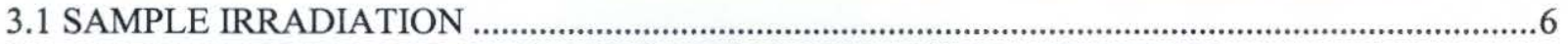

3.2 ANALYSIS OF THE HEAD SPACE GASES AFTER THE IRRADIATION ...............................8

3.3 PRE- AND POST-IRRADIATION SAMPLE CHARACTERIZATION .......................................10

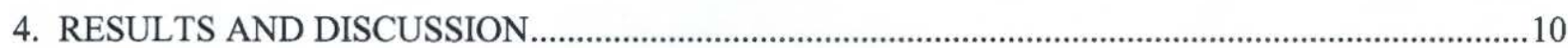

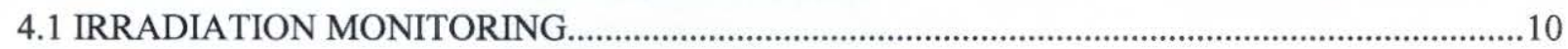

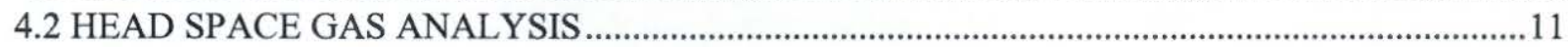

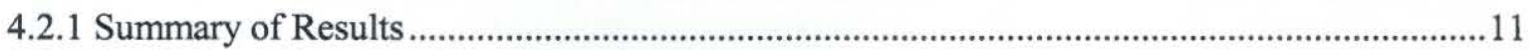

4.2.2 Analysis of Gas Sample by Mass Spectrometry .................................................................12

4.2.3 Analysis of Gas Sample by Gas Chromatography...................................................................15

4.3 PYCNOMETRIC DETERMINATION OF DENSITIES AND POROSITIES...............................18

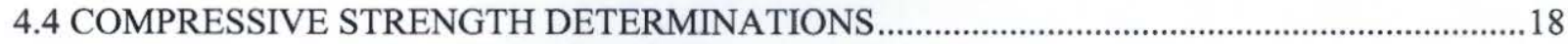

4.5 VISUAL AND MICROSCOPIC EXAMINATION OF UNIRRADIATED

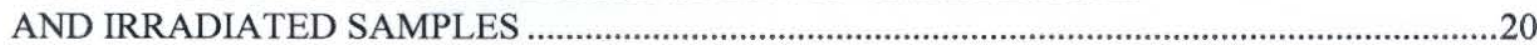

4.5.1 Optical Microscopy.............................................................................................................20

4.5.2 Scanning Electron Microscopic Analysis of Irradiated and Unirradiated Samples .................23

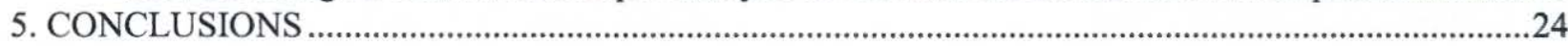

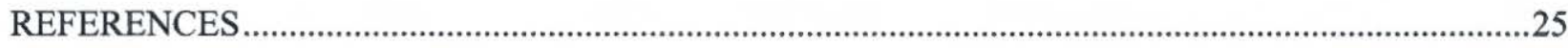


$\because$ 


\section{LIST OF FIGURES}

Figure

Page

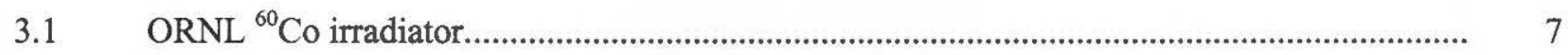

3.2 Irradiation chamber of ORNL ${ }^{60} \mathrm{Co}$ irradiator with sample containers installed.................... 7

3.3 Top of container, urethane foam, and bottom of irradiation container................................. 8

3.4 Photograph of the irradiator during the test...............................................................

3.5 Photograph of the laptop computer showing the data acquisition screen during the test. ....... 9

4.1 Pressure on the sample head space during the irradiation.................................................. 11

4.2 Mass spectrum of laboratory air collected into a Tedlar sample bag on 12/13/05 ............... 13

4.3 Mass spectrum of krypton-diluted irradiated foam atmosphere. ......................................... 13

4.4 Gas chromatograph of standards injected to identify and quantify peaks

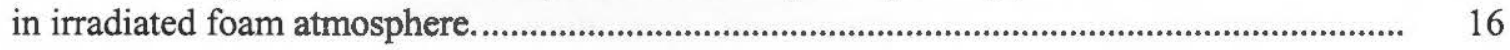

4.5 Gas chromatograph of irradiated foam atmosphere ........................................................ 17

4.6 Unconfined compressive strength for unirradiated and irradiated polyurethane

foam samples.

4.7 Irradiated foam sample after removal from the test chamber beside an unirradiated specimen.

4.8 Photograph of a unirradiated sample at $120 \times$ magnification............................................... 21

4.9 Photograph of the exposed flat surface from the irradiated sample at $120 \times$ magnification..... 22

4.10 Photograph of an internal section of the irradiated sample at $120 \times$ magnification................. 22

4.11 Scanning electron microscopy images of the irradiated sample at 50×............................ 23

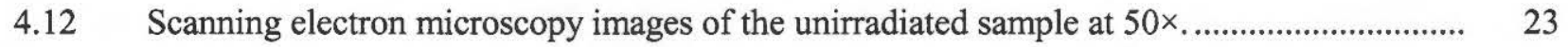


$\checkmark$

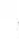

. 


\section{LIST OF TABLES}

Table

Page

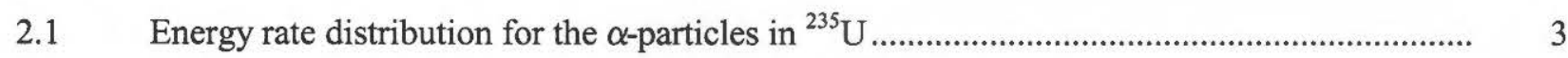

$2.2 \quad \gamma$-dose rates at various depths in the polyurethane foam ........................................................

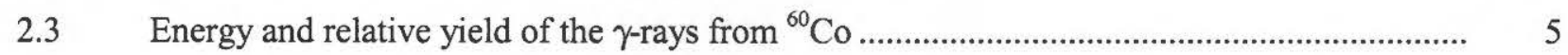

4.1 Summary of relative abundances and assignments for the mass spectrum

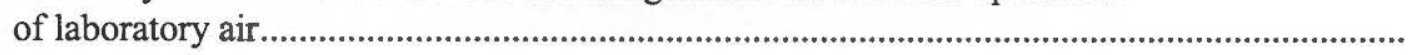

4.2 Summary of relative abundances and assignments for the mass spectrum of irradiated foam atmosphere in krypton.

4.3 Calculated percentages of major air components in the laboratory air and irradiated foam, assuming there are no other contributions to the assigned mass-to-charge values in Tables 4.1 and 4.2

4.4 Gas chromatography program conditions................................................................... 16

4.5 Calculated air components in the irradiated foam atmosphere from the gas chromatography data.

4.6 Results of pycnometric density measurements of irradiated and unirradiated urethane foam samples 



\section{ACRONYMS AND ABBREVIATIONS}

$\begin{array}{ll}\text { BJC } & \text { Bechtel Jacobs Company, LLC } \\ \text { ISA } & \text { inner surface area } \\ \text { MCNP } & \text { Monte Carlo N-Particle Transport Code System } \\ \text { ORNL } & \text { Oak Ridge National Laboratory } \\ \text { SEM } & \text { scanning electron microscopy }\end{array}$


$\because$

$\because$ 


\begin{abstract}
To facilitate the dismantling and disposal of contaminated equipment, the Bechtel Jacobs Company is evaluating the possibility of filling the cavities of pipes and parts using an impervious urethane foam to restrict the mobility of the contaminants. Samples of the urethane foam were irradiated using the Oak Ridge National Laboratory ${ }^{60} \mathrm{Co}$ irradiator to a dose equivalent to that expected to be accumulated in 1000 years for both alpha and gamma radiation. Property measurements were performed on the urethane foam samples before and after irradiation. Additionally, gas generation from the foam was monitored during irradiation and the accumulated head-space gases analyzed at the end.

The overall conclusion from the irradiation and testing is that the foam did not suffer any significant degradation during the gamma irradiation equivalent to a "1000-year alpha and gamma dose" on the entire volume of the specimen and that the gas generation was minimal.
\end{abstract}




\section{INTRODUCTION}

To facilitate the dismantling and disposal of contaminated equipment, the Bechtel Jacobs Company (BJC) is evaluating the possibility of filling the cavities of pipes and pieces using an impervious urethane foam to restrict the mobility of the contaminants. Subsequently the infiltrated pipes and parts will be sent to a sub-surface repository for disposal. For this purpose, the long-term stability and durability of the foam needs to be investigated. One of the important aspects to be analyzed is the possible radiolytic degradation of the urethane foam.

The $\mathrm{K} 25 / 27$ process pipe is assumed to have $2 \mathrm{~g}$ of ${ }^{235} \mathrm{U}$ distributed uniformly over the inner surface of an 18 -inch length of 8 -inch-diam pipe. The pipe is assumed to be stainless steel with a wall thickness of $0.22 \mathrm{in}$. The pipe was to be filled with polyurethane foam at $3.5 \mathrm{lb} / \mathrm{ft}^{3}$.

Samples of the urethane foam were irradiated with gamma radiation to evaluate the degradation. Property measurements were performed before and after irradiation. Additionally, gas generation from the foam during irradiation was measured. The material was irradiated, using the Oak Ridge National Laboratory (ORNL) ${ }^{60} \mathrm{Co}$ irradiator, to a dose equivalent to that expected to be generated by the presence of the uranium contamination during a period of 1000 years. Most of the radiation dose from the uranium will be in the form of alpha particles reaching only the outer skin layer. Therefore, the surface of the polyurethane foam will absorb a much higher dose than the bulk of the sample. Accordingly, most of the radiation damage will be confined to the surface of the polyurethane in close proximity to the uranium contamination.

The penetrating gamma rays from ${ }^{60} \mathrm{Co}$ will reach the entire volume of the foam sample. To evaluate the radiation damage to the polyurethane surface, the entire sample was irradiated at the higher level of exposure that otherwise would be experienced only by the outer surface. Obviously, this is a very conservative test, and positive results should give a significant degree of confidence regarding the radiation stability of the polyurethane foam. A more realistic description of the radiation effects can be construed from the irradiation tests by envisioning a core of lightly irradiated foam surrounded by a thin skin of the more heavily irradiated material. 


\section{DOSE AND RESIDENCE TIME CALCULATIONS}

To proceed with the execution of the projected scope, the first steps were to calculate the amount of dose imparted to the polyurethane by uranium contamination during a span of 1000 years, and the residence time in the ${ }^{60} \mathrm{Co}$ irradiator to impart an alpha equivalent dose.

\subsection{SUMMARY OF DOSE AND RESIDENCE TIME CALCULATIONS EQUIVALENT TO 1000 YEARS EXPOSURE}

As previously indicated, the $\mathrm{K} 25 / 27$ process pipe is assumed to have $2 \mathrm{~g}$ of ${ }^{235} \mathrm{U}$ distributed uniformly on the inner surface over an 18-in. length of 8 -in.-diam pipe. The pipe is assumed to be stainless steel with a wall thickness of $0.22 \mathrm{in}$. The pipe is to be filled with polyurethane foam at $3.5 \mathrm{lb} / \mathrm{ft}^{3}$. Samples of the urethane foam will be irradiated with gamma radiation to evaluate the degradation at a level equivalent to that expected to be generated by the presence of the uranium contamination during a period of 1000 years. The calculated 1000-year alpha dose to the polyurethane is $2.56 \times 10^{7} \mathrm{rad}$, and it will affect only a very thin layer at the surface of the polyurethane foam. The 1000-year gamma dose to the polyurethane is 324 $\mathrm{rad}$ as an average over the volume of material.

The penetrating gamma rays from ${ }^{60} \mathrm{Co}$ will reach the entire volume of the foam sample; so the whole sample, and not just the surface, will be irradiated at the 1000 -year alpha dose of $2.56 \times 10^{7} \mathrm{rad}$. The residence time calculations showed that the 1000-year alpha dose equivalent will require 24.2 days of irradiation at the ORNL ${ }^{60} \mathrm{Co}$ irradiator. The equivalent gamma dose requires only $26.5 \mathrm{~s}$ and in practice can be neglected. The detailed calculations are shown in Sects. 2.2 and 2.3.

\subsection{DOSE CALCULATIONS}

To determine the alpha dose to the foam, the ${ }^{235} \mathrm{U}$ alpha energies and corresponding fractions were taken from ref. 1. The inner surface area (ISA) of the pipe is given by $2 \pi r l$; where $r$ is the inner radius of the pipe (4 in. minus wall thickness) and $l$ is the length of the pipe:

$$
I S A=2 \pi \times(4 \times 2.54 \mathrm{~cm}-0.55 \mathrm{~cm}) \times 45.72 \mathrm{~cm}=2760.6 \mathrm{~cm}^{2} .
$$

Reference 2 gives the specific activity of ${ }^{235} \mathrm{U}$ as $2.2 \times 10^{-6} \mathrm{Ci} / \mathrm{g}$. The $2 \mathrm{~g}$ would produce an activity of $4.4 \times 10^{-6}$ curies distributed over the inner pipe surface, or $4.4 \times 10^{-6} \mathrm{Ci} / 2760.6 \mathrm{~cm}^{2}=1.594 \times 10^{-9}$ $\mathrm{Ci} / \mathrm{cm}^{2}$ :

Energy rate $=3.7 \times 10^{10} \mathrm{dis} / \mathrm{s}$ per $\mathrm{Ci} \times 1.594 \times 10^{-9} \mathrm{Ci} / \mathrm{cm}^{2} \times \alpha$ energy $\mathrm{MeV} \times$ fraction 
For the inner pipe surface, the contribution to the total energy rate from each alpha energy is shown in Table 2.1.

Table 2.1. Energy rate distribution for the $\alpha$-particles in ${ }^{235} \mathrm{U}$

\begin{tabular}{lll}
\hline Energy $(\mathrm{MeV})$ & Fraction & Energy rate $\left(\mathrm{eV} / \mathrm{cm}^{2} \times \mathrm{s}\right)$ \\
\hline 4.2 & 0.075 & 18.6 \\
4.3 & 0.065 & 16.5 \\
4.4 & 0.751 & 194.1 \\
4.5 & 0.017 & 4.5 \\
4.6 & 0.092 & 25 \\
\hline Total & 1.000 & 258.7 \\
\hline
\end{tabular}

The total amount of energy per unit area per second is the sum that is $258.7 \mathrm{MeV} / \mathrm{cm}^{2} \times \mathrm{s}$, and the amount directed toward the polyurethane foam is half of that or $129.4 \mathrm{MeV} / \mathrm{cm}^{2} \times \mathrm{s}$. The range in organic polymers $\left(\mathrm{CH}_{2}\right)$ in $\mathrm{mg} / \mathrm{cm}^{2}$ is given in ref. 3 for $4.0026-\mathrm{MeV}$ alpha particles as 2.078 and for $5.0033-\mathrm{MeV}$ alphas as 2.881. Interpolation for 4.4- and 4.6-MeV energies gives:

$$
\begin{aligned}
& x=2.078+0.3974 \times(2.881-2.078)=2.397 \text { for } 4.4 \mathrm{MeV} \text { and } \\
& x=2.078+0.5974 \times(2.881-2.078)=2.558 \text { for } 4.6 \mathrm{MeV}
\end{aligned}
$$

Table II of ref. 3 gives the unit conversion factor for converting $\mathrm{mg} / \mathrm{cm}^{2}$ to $\mathrm{mm}$ of polymer as $0.01 / \rho$, where $\rho$ is the density of the material. The density of the polyurethane was given as $0.05 \mathrm{~g} / \mathrm{cm}^{3}$, which gives a multiplier of $0.01 / 0.05=0.2$.

The range for the 4.4-MeV alphas is then $0.2 \times 2.397=0.4794 \mathrm{~mm}=0.04794 \mathrm{~cm}$; and for the 4.6-MeV alphas, it is $0.2 \times 2.558=0.5116 \mathrm{~mm}=0.05116 \mathrm{~cm}$. It is therefore reasonable to assume almost all of the energy is absorbed by a depth of $0.05116 \mathrm{~cm}$ in the polyurethane foam. For the unit area, the volume into the foam would be $1 \mathrm{~cm} \times 1 \mathrm{~cm} \times 0.05116 \mathrm{~cm}=0.05116 \mathrm{~cm}^{3}$. Given a density of $0.05 \mathrm{~g} / \mathrm{cm}^{3}$, this volume represents $0.002558 \mathrm{~g}$ of sample.

Thus we have

$(129.4 \mathrm{MeV} / \mathrm{s} / 0.002558 \mathrm{~g}) \times 1.6021 \times 10^{-6} \mathrm{erg} / \mathrm{MeV} \times 3600 \mathrm{~s} / \mathrm{h}=291.8 \mathrm{erg} / \mathrm{g} \mathrm{per} \mathrm{h}=2.92 \mathrm{rad} / \mathrm{h}$. 
The dose rate due to alphas calculated by this method is $2.92 \mathrm{rad} / \mathrm{h}$. It is absorbed within a depth of about $0.05116 \mathrm{~cm}$ into the polyurethane foam. The 1000 -year alpha dose to the polyurethane is $2.56 \times 10^{7} \mathrm{rad}$.

The dose rate due to gamma rays was determined by modeling the pipe/foam configuration and inputting it with the gamma energy spectrum ${ }^{1}$ into the MCNP4C code. The gamma/s rate was calculated to be $1.94 \times 10^{5}$ gamma/s for $2 \mathrm{~g}$ of ${ }^{235} \mathrm{U}$. The Monte Carlo N-Particle Transport Code System (MCNP) output was given in $\mathrm{MeV} / \mathrm{g}$ averaged within the whole volume of the polyurethane foam. The result is $3.30304 \times 10^{-6} \mathrm{MeV} / \mathrm{g}$. Thus $3.30304 \times 10^{-6} \mathrm{MeV} / \mathrm{g}$ per gamma $\times 1.94 \times 10^{5} \mathrm{gammas} / \mathrm{s}=0.64078976$ $\mathrm{MeV} / \mathrm{g}$ per second $\times 1.6021 \times 10^{-6} \mathrm{erg} / \mathrm{MeV} \times 3600 \mathrm{~s} / \mathrm{h}=0.003695793 \mathrm{erg} / \mathrm{g}$ per $\mathrm{h}=3.7 \times 10^{-5} \mathrm{rad} / \mathrm{h}=$ $0.037 \mathrm{mrad} / \mathrm{h}$. The gamma dose rate is calculated to be $0.037 \mathrm{mrad} / \mathrm{h}$ in the polyurethane foam. The $1000-$ year gamma dose to the polyurethane is $324 \mathrm{rad}$. This result is the average over the volume of material. MCNP runs were done to evaluate dose rates (by energy deposition) at various depths within the poly foam also. The results calculated are shown in Table 2.2 .

Table 2.2. $\gamma$-dose rates at various depths in the polyurethane foam

\begin{tabular}{lcc}
\hline Depth & Dose rate $(\mathrm{rad} / \mathrm{h})$ & 1000 -year dose $(\mathrm{rad})$ \\
\hline Surface to 1 in. & $4.70 \times 10^{-5}$ & 411.85 \\
1 to 2 in. & $3.02 \times 10^{-5}$ & 264.59 \\
2 to 3 in. & $2.61 \times 10^{-5}$ & 229.06 \\
3 to 4 in. & $2.48 \times 10^{-5}$ & 217.46 \\
\hline
\end{tabular}

\subsection{CALCULATION OF THE RESIDENCE TIME IN THE ${ }^{60}$ CO IRRADIATOR TO ACHIEVE A 1000-YEAR DOSE}

The 1000-year dose for the polyurethane foam was found to be $324 \mathrm{rad}$ of gamma, averaged over the volume, and $2.56 \times 10^{7} \mathrm{rad}$ of alpha. As mentioned, we will calculate a residence time in the ${ }^{60} \mathrm{Co}$ irradiator so as to impart the maximum calculated dose located at the surface to the whole volume of the polyurethane foam.

The method used to estimate the residence time models the ${ }^{60} \mathrm{Co}$ irradiation chamber using the gamma energy spectrum and fractions obtained from ref. 1 . This radiation decay program was developed by Grove Engineering, Inc. The resulting energies and corresponding fractions are shown in Table 2.3. 
Table 2.3. Energy and relative yield of the $\gamma$-rays from ${ }^{60} \mathrm{Co}$

\begin{tabular}{ll}
\hline Energy $(\mathrm{MeV})$ & Fraction \\
\hline 0.693820 & 0.000163 \\
1.173200 & 1.000000 \\
1.332500 & 1.000000 \\
\hline
\end{tabular}

The material inside the chamber was modeled as air, and the result was given in $\mathrm{MeV} /$ gram for a volume of air in the center of the irradiation chamber. The exposure rate profile for the ${ }^{60} \mathrm{Co}$ irradiation chamber was obtained from ref. 4 and from an exposure of $1.85 \times 10^{6} \mathrm{R} / \mathrm{h}$ on December 9,1977 . Given the half-life of ${ }^{60} \mathrm{Co}$ of 5.271 years and the lapsed time to October 31, 2005, of 27.8932 years, the exposure rate for October 31, 2005, was calculated to be

$$
\left(1.85 \times 10^{6} \mathrm{R} / \mathrm{h}\right) \times \mathrm{e}^{(-\ln 2 / 5.271 \times 27.8932)}=47,225 \mathrm{R} / \mathrm{h}
$$

In air: $1 \mathrm{R}=87.6 \mathrm{erg} / \mathrm{g} ; \quad$ therefore, $47,225 \mathrm{R} \times 87.6 \mathrm{erg} / \mathrm{g}$ per $\mathrm{R}=4,136,910 \mathrm{erg} / \mathrm{g} \mathrm{per} \mathrm{h}$.

Since we have $1.6021 \times 10^{-6} \mathrm{erg} / \mathrm{MeV}$, that would be $4,136,910 \mathrm{erg} / \mathrm{g} \div 1.6021 \times 10^{-6} \mathrm{erg} / \mathrm{MeV}=$ $2.58218 \times 10^{12} \mathrm{MeV} / \mathrm{g}$ per $\mathrm{h}=7.17272 \times 10^{8} \mathrm{MeV} / \mathrm{g}$ per second in air. The model for the source in MCNP was considered to be a cylindrical distribution at the surface of the irradiation chamber. The result from MCNP for air in the chamber was $3.56048 \times 10^{-5} \mathrm{MeV} / \mathrm{g}$ per gamma per second. Thus if we call the number of gammas per second $\gamma$, we have

$$
3.56048 \times 10^{-5} \mathrm{MeV} / \mathrm{g} \times \gamma=7.17272 \times 10^{8} \mathrm{MeV} / \mathrm{g} \text { per second } .
$$

Then $\gamma=7.17272 \times 10^{8} \div 3.56048 \times 10^{-5}=2.01454 \times 10^{13}$ starting gammas per second.

Next, the $3.5 \times 4$-in. foam sample in the stainless steel container was modeled in the center of the irradiation chamber in MCNP. This time, the energy deposition ( $\mathrm{MeV} / \mathrm{g}$ per starting gamma) in the polyurethane foam was the output. The MCNP result is $3.78439 \times 10^{-5}$. Thus we have

$$
\begin{gathered}
3.78439 \times 10^{-5} \mathrm{MeV} / \mathrm{g} \times 2.01454 \times 10^{13} \mathrm{gamma} / \mathrm{s}=7.6238 \times 10^{8} \times 3600 \mathrm{~s} / \mathrm{h}=2.744569811 \\
\times 10^{12} \mathrm{MeV} / \mathrm{g} \text { per h } \times 1.6021 \times 10^{-6} \mathrm{erg} / \mathrm{MeV}=4,397,075 \mathrm{erg} / \mathrm{g} \text { per } \mathrm{h} .
\end{gathered}
$$

$4,397,075 \mathrm{erg} / \mathrm{g}$ per $\mathrm{h} \div 100 \mathrm{erg} / \mathrm{g}$ per $\mathrm{rad}=43,970.75 \mathrm{rad} / \mathrm{h}$ in the polyurethane foam.

Consequently, the alpha dose of $2.558 \times 10^{7} \mathrm{rad}$ would take $2.558 \times 10^{7} \mathrm{rad} \div 43,970.75 \mathrm{rad} / \mathrm{h}=$ $581.75 \mathrm{~h}$ or about 24.24 days to obtain. Similarly, the gamma dose of 324.12 rad would take $324.12 \mathrm{rad} \div 43,970.75 \mathrm{rad} / \mathrm{h}=7.37 \times 10^{-3} \mathrm{~h}$, or about 26.5 seconds to obtain. 


\section{EXPERIMENTAL}

The experimental program was divided into three distinct activities: sample irradiation, analysis of the head space gases after the irradiation, and polyurethane foam characterization before and after irradiation.

\subsection{SAMPLE IRRADIATION}

Radiolysis experiments were performed using gamma irradiation at a level equivalent to the combined alpha and gamma doses from uranium contamination over a period of 1000 years. The foam irradiation experiment was performed using the J. L. Shepherd model 109-68 (serial no. 654) ${ }^{60}$ Co gamma irradiator shown in Fig. 3.1. It emits 1.1173-MeV and 1.332-MeV gamma rays that provide a dose rate of about $47000 \mathrm{rad} / \mathrm{h}$. The irradiation container itself is shown in Fig. 3.1, while Fig. 3.2 shows some previous samples installed in the irradiator before being lowered into the device.

A cylindrical foam sample, 3.5 in. diam and 4 in. high, provided by Dileep Singh from Argonne National Laboratory, was contained in a high-integrity stainless steel vessel. The vessel was constructed in two parts, as shown in Fig 3.3.

The top of the container has two stainless steel Nupro ${ }^{\circledR}$ valves that allow the container to be connected to a pressure transducer and allow sampling of the head space. As shown in Fig. 3.3, the top of the container has a metal O-ring integrated to the body. This O-ring is slightly larger than the internal diameter of the bottom part. In order to close the container, the top is cooled with liquid nitrogen so the metal will contract. In this "cold" state, the top fits loosely inside the bottom part. However, once the top part is allowed to warm at room temperature, the metal O-ring expands, making a metal-to-metal highintegrity seal. To open the container, the process is reversed. After sample loading and sealing, the vessel was leak tested with air at a pressure of 30 Psig. 


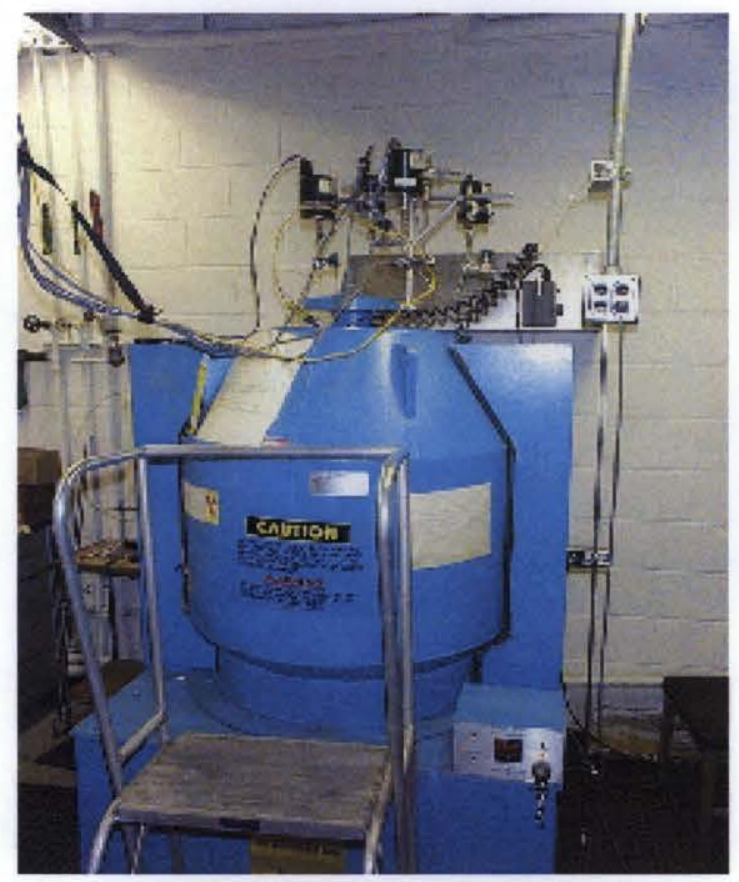

Fig. 3.1. ORNL ${ }^{60} \mathrm{Co}$ irradiator.

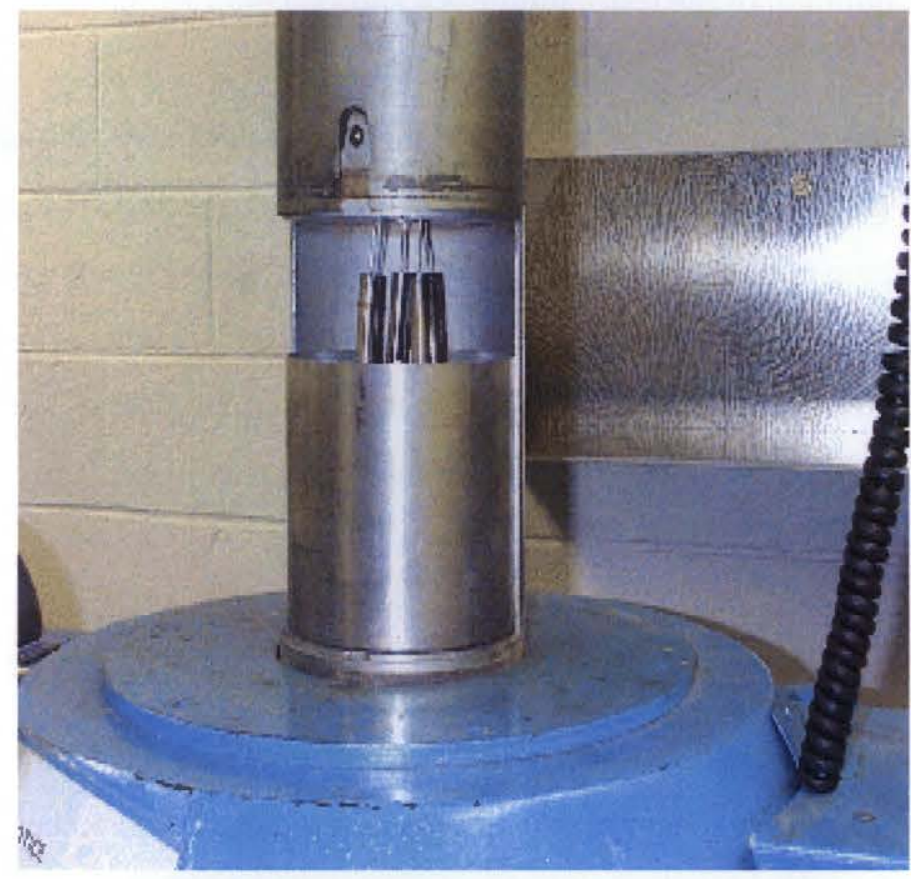

Fig. 3.2. Irradiation chamber of ORNL ${ }^{60} \mathrm{Co}$ irradiator with sample containers installed. 


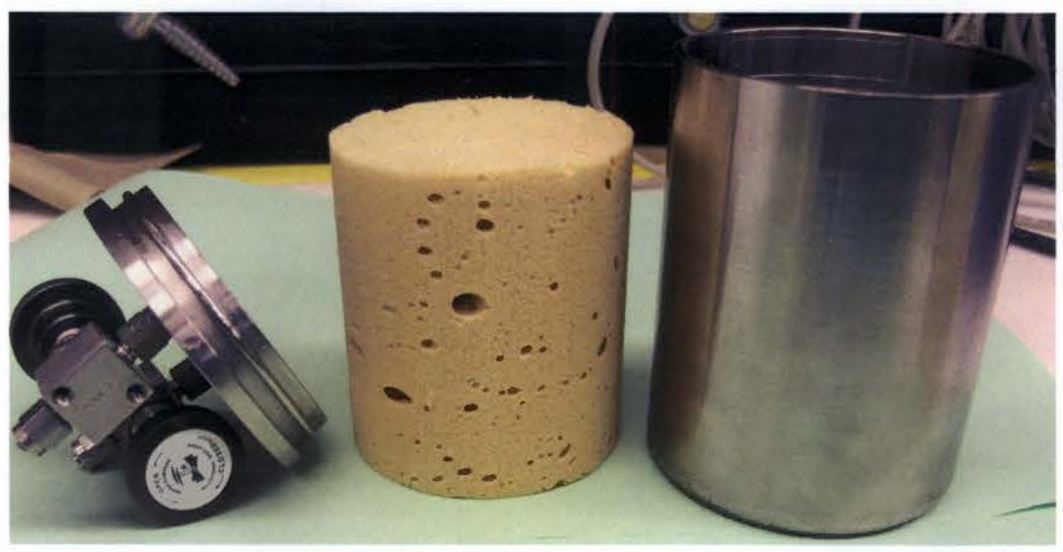

Fig. 3.3. Top of container, urethane foam, and bottom of irradiation container.

The container was connected by small-diameter tubing to an MKS Baratron ${ }^{\circledR}$ pressure transducer (Type 627 B13TB1CB) calibrated by the ORNL metrology laboratory. A type K thermocouple was attached to the external surface of the sample vessel. The sample vessel was then inserted into the irradiator container for the duration of the test. Figure 3.4 shows a photograph of the irradiator during the test.

A computerized data acquisition system was used to collect data during each irradiation. The data acquisition consisted of an OMEGA OMB-DAQ-56 external board connected via the USB interface to a Compaq Presario R3000 laptop computer operating under the Windows XP operating system. The software Personal DAQ View version 2.0.4 supplied with the OMEGA board was used for a data acquisition, which included the periodic recording of temperature and pressure of the irradiation vessel. Figure 3.5 shows the laptop screen while the data acquisition was taking place. The data were backed up daily.

\subsection{ANALYSIS OF THE HEAD SPACE GASES AFTER THE IRRADIATION}

At the end of the irradiation, the vessel containing the sample was removed from the irradiation cavity. The valve connected to the pressure transducer was closed and the tubing disconnected. The valve was then capped using a Swagelok plug, and the container was shipped to MCL, Inc., for analysis of the head space gases by mass spectrometry and gas chromatography. ${ }^{5}$ 


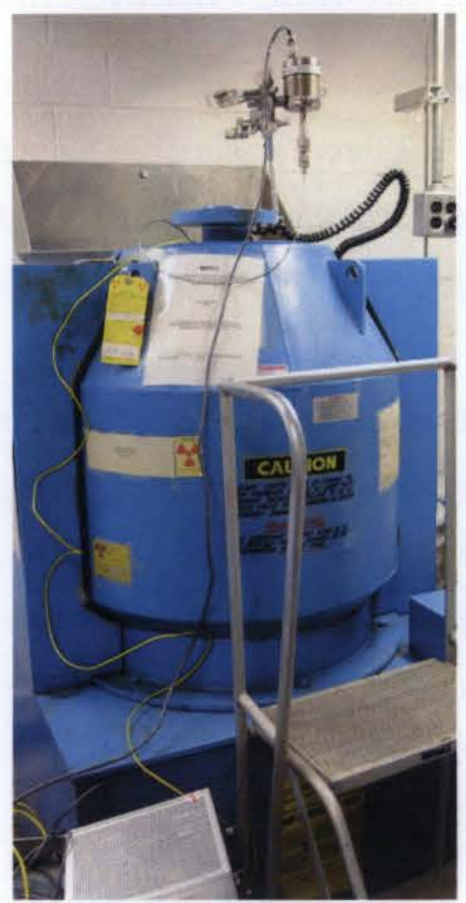

Fig. 3.4. Photograph of the irradiator during the test.

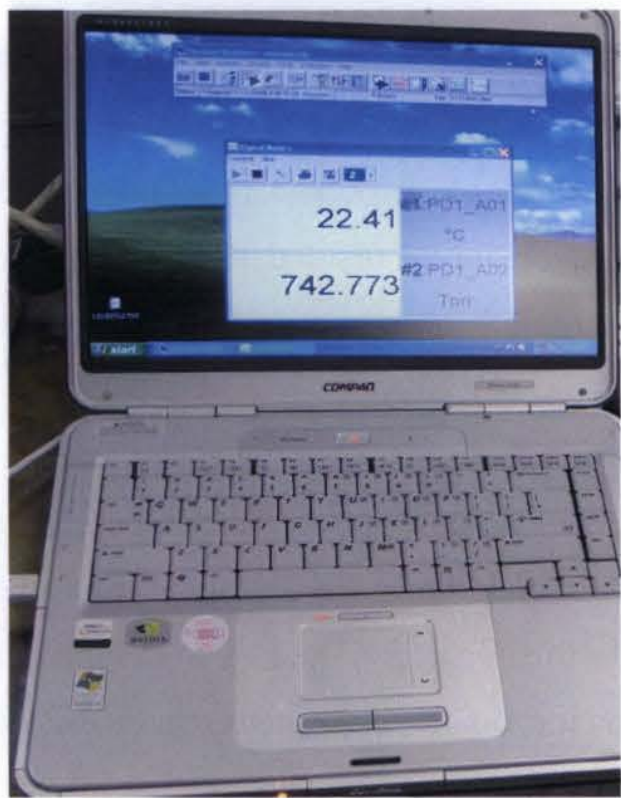

Fig. 3.5. Photograph of the laptop computer showing the data acquisition screen during the test. 


\subsection{PRE- AND POST-IRRADIATION SAMPLE CHARACTERIZATION}

At completion of the head space gas analysis, the vessel containing the sample was returned to ORNL for the post-irradiation sample testing. The three remaining specimens, of the four originally received, were used to determine the properties of the unirradiated samples and to make comparisons to the irradiated specimen. The property measurements included compressive strength, density, porosity, and visual and microscopic examination.

An Ultrapycnometer Model 1000 manufactured by Quantachrome Corporation was used to determine the pycnometric densities and connected porosities of polyurethane samples before and after irradiation. An Olympus optical microscope with a Moticam2000 camera interfaced to a PC with Motic Images software was used for the visual evaluation of the specimens. Scanning electron microscopy (SEM) images were also obtained from unirradiated and irradiated specimens to search for any structural differences that could be attributed to radiation damage.

\section{RESULTS AND DISCUSSION}

\subsection{IRRADIATION MONITORING}

Pressure within the sample and the temperature of the container were monitored throughout the irradiation; the pressure data are shown in Fig. 4.1. The temperature inside the irradiator fluctuated with the room temperature between a minimum of $21.0^{\circ} \mathrm{C}$ and a maximum of $23.7^{\circ} \mathrm{C}$. As shown, the pressure on the head space remained mostly stable for the first 5 days, slightly diminished during the following 5 days, and then remained somewhat stable for the remainder of the irradiation. Note that the initial pressure represents that of the radiological facility (Building 4501) that houses the irradiator and that the pressure in the building is maintained below atmospheric pressure for radiological containment purposes.

The main conclusion from the monitoring of the pressure of the head space is that the gamma irradiation of the urethane sample was not followed by any significant generation of gaseous species. The slight reduction in pressure can be attributed to radiolysis of air to form nitrogen oxide gases that, in the presence of humidity, condensed on the sample and container surfaces. A detailed report on the head space gases follows in Sect. 4.2. 


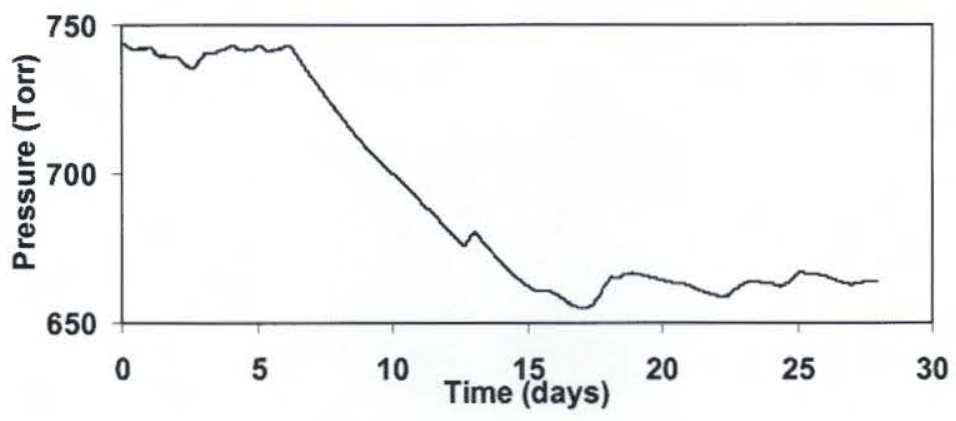

Fig. 4.1. Pressure on the sample head space during the irradiation.

\subsection{HEAD SPACE GAS ANALYSIS}

After irradiation, the container was under a slight vacuum. To proceed with the sampling of the head space gases, a quantity of krypton was added to slightly pressurize the vessel. The contents of the sample chamber were then vented to a Tedlar sampling bag.

Complementary analysis of the head space gases was accomplished using a combination of gas chromatography and mass spectrometry.

\subsubsection{Summary of Results}

Mass spectrometry of the irradiated foam atmosphere showed that the concentration of nitrogen and oxygen had decreased and that the concentration of water and carbon dioxide had increased with respect to the initial air. From the relative abundance, the molar concentrations were determined to be $\mathrm{N}_{2}=52.66 \%$, $\mathrm{O}_{2}=4.05 \%, \mathrm{H}_{2} \mathrm{O}=28.52 \%$, and $\mathrm{CO}_{2}=10.26 \%$. These calculated concentrations assume that there were no other contributions to the parent mass-to-charge values for nitrogen, oxygen, water, and carbon dioxide. The water concentration calculated by attributing the mass value of 18 was much greater than saturation at room temperature, but no liquid water was evident during sampling. Since dry krypton gas was used for sampling, some of the water may have been transported by the krypton from the surface of the foam; however, the value is still higher than expected. It is highly plausible that another species with mass 18 is present (e.g., $\mathrm{NH}_{4}^{+}$).

Gas chromatography confirmed the presence of nitrogen, carbon dioxide, and hydrogen in the irradiated foam atmosphere. The concentrations were determined to be $\mathrm{N}_{2}=53.97 \%, \mathrm{CO}_{2}=8.36 \%$. and $\mathrm{H}_{2}=1.48 \%$. Other species like water were not detectable given the chromatographic conditions used. The agreement between mass spectrometry and gas chromatography is quite reasonable. ${ }^{5}$ 
$\therefore$

$\downarrow$

2 


\subsubsection{Analysis of Gas Sample by Mass Spectrometry}

The sample was drawn into a Hewlett Packard 5989A mass spectrometer at a rate of $5 \mathrm{cc} / \mathrm{min}$. A mass spectrum was obtained on the diluted, irradiated foam atmosphere from 3 to 80 amu using $70 \mathrm{eV}$ ionization potential. Laboratory room air in a Tedlar bag was used as a reference sample because this was the original atmosphere before irradiation. Figures 4.2 and 4.3 show the mass spectra of the air and the diluted foam atmosphere, and Tables 4.1 and 4.2 summarize the mass spectra with the relative abundances (>1\%) and composition assignments.

Note that because of the limitation of the instrument, it was not possible to scan below 3 amu and detect hydrogen in a reproducible fashion. In addition, since nitrogen and carbon monoxide have the same nominal mass-to-charge ratio, we were not able to differentiate between nitrogen and carbon monoxide; hence, we have reported the mass-to-charge value at 28 as nitrogen only. However, since carbon monoxide was not detected in the gas chromatography work, the previous assumption is quite reasonable.

Quantification of the major components in Tables 4.1 and 4.2 was accomplished using the relative abundance data and argon as the internal standard. Table 4.3 summarizes the results, which show that the nitrogen and oxygen concentrations have decreased to 52.66 and $4.05 \%$, respectively (vs. 77.30 and $20.74 \%$ for laboratory room air); and the water and carbon dioxide concentrations have increased to 28.52 and $10.26 \%$, respectively (vs. 0.99 and $0.03 \%$ for laboratory room air). Note that these calculations assume that there are no other contributions to the assigned mass-to-charge values in Tables 4.1 and 4.2. The high calculated water concentration suggests that there may be an additional contribution to the $\mathrm{m} / \mathrm{e}$ value of 18 (e.g., $\mathrm{NH}_{4}^{+}$) because at $26^{\circ} \mathrm{C}$ and $100 \%$ relative humidity, the mole percentage in air should not exceed $3.3 \%$. No liquid water was evident when the foam atmosphere was sampled. Humidity impregnated in the foam may have been carried out by the injection of dry krypton, but the value for mass 18 is still somewhat too high.

The mass spectrum of the irradiated foam atmosphere also showed several additional compounds or fragments at mass-to-charge ratios of 51,64, and 69. These signals are not consistent with the parent or fragments from the proprietary foam composition. The National Institute of Standards and Technology Mass Spectral Library search produced no hits for $\mathrm{m} / \mathrm{e}$ of 51, ethylchloride and 2-fluoroethanol for $\mathrm{m} / \mathrm{e}$ of 64, and 2-propyn-1-amine N-methyl, 1-H-Pyrrole 2,5-dihydro, and isobutyronitrile for m/e of 69. A fluorinated hydrocarbon is feasible because a fluorinated hydrocarbon is used as a blowing agent in the foam. 


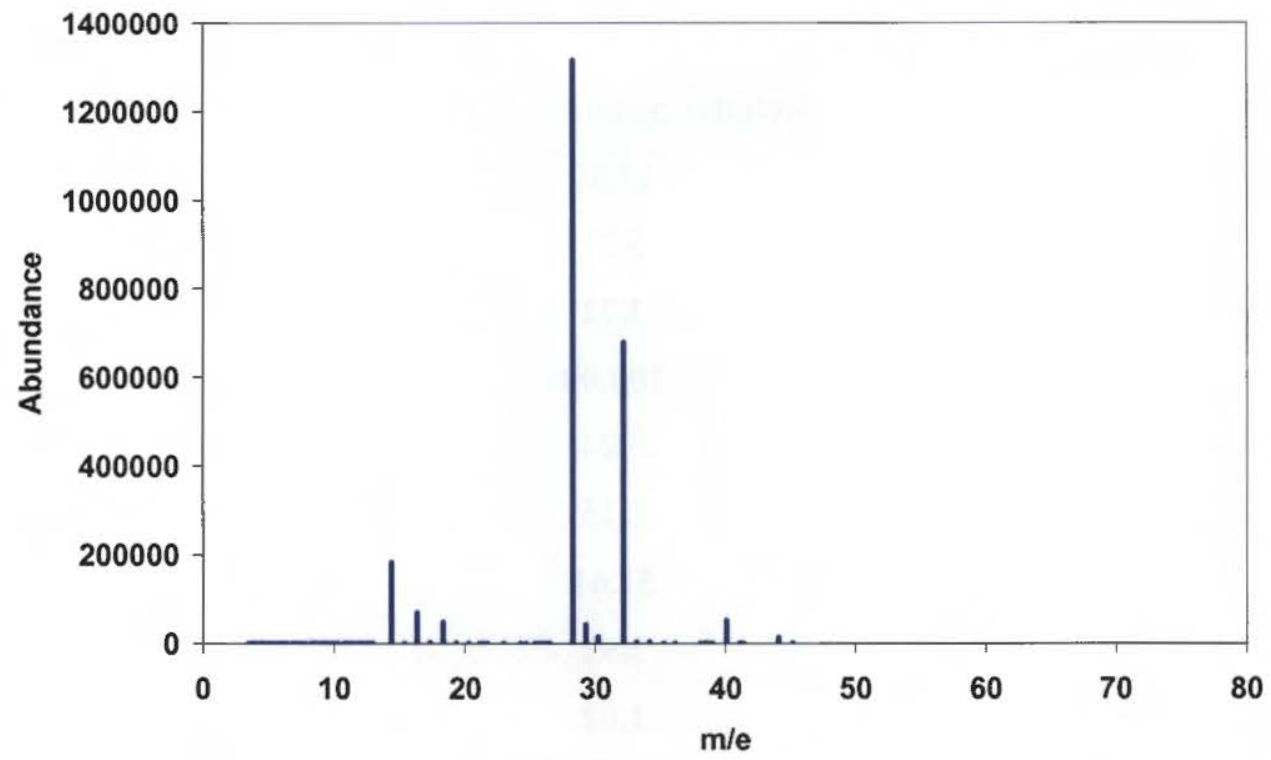

Fig. 4.2. Mass spectrum of laboratory air collected into a Tedlar sample bag on 12/13/05.

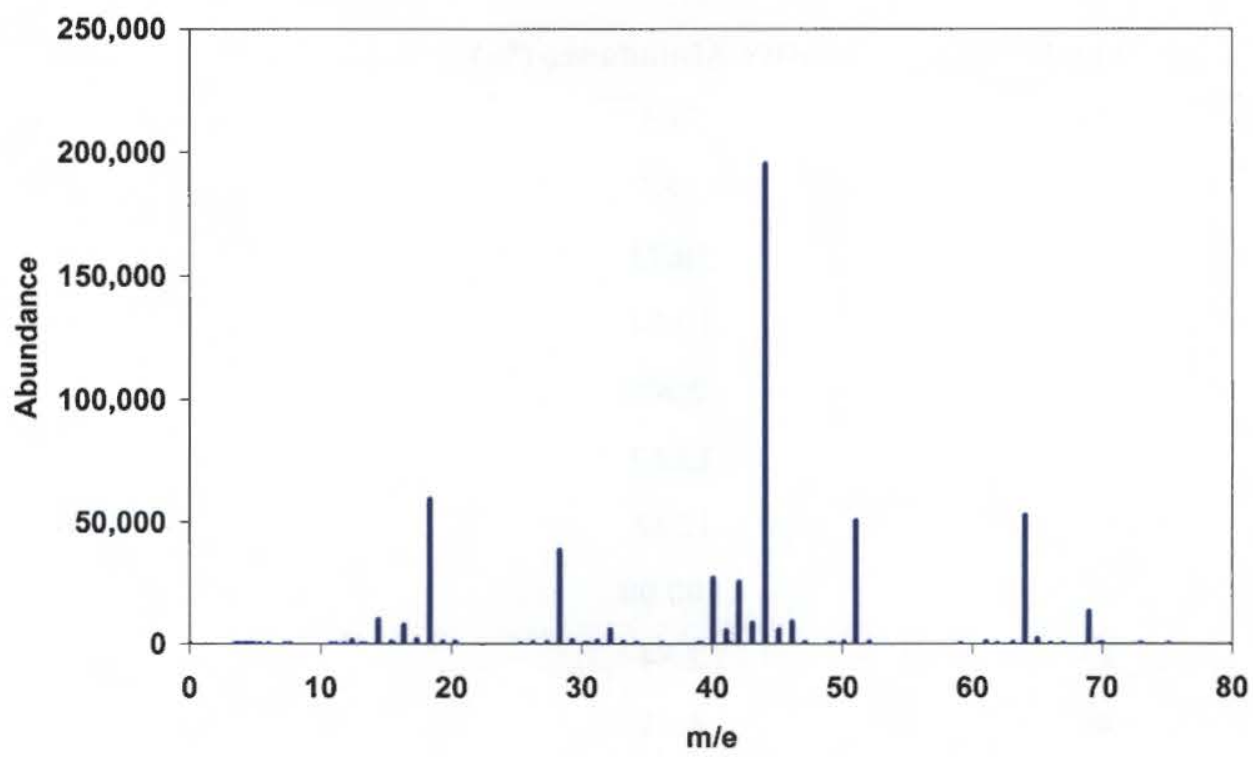

Fig. 4.3. Mass spectrum of krypton-diluted irradiated foam atmosphere. 
Table 4.1. Summary of relative abundances and assignments for the mass spectrum of laboratory air (Fig. 4.2)

\begin{tabular}{ccc}
\hline $\mathbf{m} / \mathbf{e}$ & Relative abundance (\%) & Assignment \\
\hline 14 & 13.89 & $\mathrm{~N} ?$ \\
16 & 5.31 & $\mathrm{CH} 4 ?, \mathrm{O} ?$ \\
18 & $\mathbf{3 . 7 2}$ & Water \\
28 & $\mathbf{1 0 0 . 0 0}$ & Nitrogen \\
29 & 3.24 & - \\
30 & 1.15 & NO? \\
32 & $\mathbf{5 1 . 6 1}$ & Oxygen \\
40 & $\mathbf{3 . 9 2}$ & Argon \\
44 & $\mathbf{1 . 0 2}$ & Carbon dioxide
\end{tabular}

Table 4.2. Summary of relative abundances and assignments for the mass spectrum of irradiated foam atmosphere in krypton (Fig. 4.3)

\begin{tabular}{ccc}
\hline m/e & Relative Abundance (\%) & Assignment \\
\hline 14 & 5.05 & N? \\
16 & 3.87 & O?, CH4? \\
18 & $\mathbf{3 0 . 7 3}$ & Water + other \\
28 & $\mathbf{1 9 . 5 4}$ & Nitrogen \\
32 & $\mathbf{2 . 8 9}$ & Oxygen \\
40 & $\mathbf{1 3 . 6 7}$ & Argon \\
42 & 12.88 & - \\
44 & $\mathbf{1 0 0 . 0 0}$ & Carbon dioxide \\
45 & 2.84 & - \\
46 & 4.51 & NO2? \\
51 & 25.76 & - \\
64 & 27.02 & - \\
65 & 1.04 & - \\
69 & 6.72 & - \\
\hline
\end{tabular}


Table 4.3. Calculated percentages of major air components in the laboratory air and irradiated foam, assuming there are no other contributions to the assigned mass-to-charge values in Tables 4.1 and $\mathbf{4 . 2}$

\begin{tabular}{ccc}
\hline $\begin{array}{c}\text { Air component } \\
(\text { mol \%) }\end{array}$ & Laboratory air & Irradiated foam atmosphere $^{a}$ \\
\hline Water (\%) & $0.99^{b}$ & $28.52^{c}$ \\
Nitrogen (\%) & 77.30 & $52.66^{d}$ \\
Oxygen (\%) & 20.74 & 4.05 \\
Carbon dioxide (\%) & 0.03 & 10.26 \\
\hline
\end{tabular}

${ }^{a}$ Corrected for dilution by krypton with argon $\mathrm{m} / \mathrm{e}$ signal.

${ }^{b}$ Estimated from room temperature of $26^{\circ} \mathrm{C}$ and $30 \%$ relative humidity.

${ }^{c}$ Includes other species having a mass-to-charge value of 18 .

${ }^{d}$ Assumes no carbon monoxide present.

Based on ref. 6, the following assignments are also possible for the mass-to-charge ratios of 51, 64, and 69:

51: $\mathrm{C}_{4} \mathrm{H}_{3}$

64: $\mathrm{CH}_{4} \mathrm{O}_{3}, \mathrm{C}_{4} \mathrm{H}_{2} \mathrm{~N}, \mathrm{C}_{5} \mathrm{H}_{4}$

69: $\mathrm{CHN}_{4}, \mathrm{C}_{2} \mathrm{HN}_{2} \mathrm{O}, \mathrm{C}_{2} \mathrm{H}_{3} \mathrm{~N}_{2}, \mathrm{C}_{3} \mathrm{HO}_{2}, \mathrm{C}_{3} \mathrm{H}_{3} \mathrm{NO}, \mathrm{C}_{3} \mathrm{H}_{5} \mathrm{~N}_{2}, \mathrm{C}_{4} \mathrm{H}_{5} \mathrm{O}, \mathrm{C}_{4} \mathrm{H}_{7} \mathrm{~N}, \mathrm{C}_{5} \mathrm{H}_{9}$

With the decrease in nitrogen in the foam atmosphere, nitrogen containing carbon compounds are likely; however, additional work will be required for complete identification.

\subsubsection{Analysis of Gas Sample by Gas Chromatography}

An Antek 3000 gas chromatograph with a Supelco 100/120 HayeSep D column was used to analyze the krypton-diluted, irradiated foam atmosphere. Argon was used as the carrier, and a thermal conductivity detector was used with a WINDAQ data acquisition computer interface. The chromatographic conditions are listed in Table 4.4.

The sample was pushed from a Tedlar sample bag through a 1.2-cc sample loop and then injected (standards were loaded from the appropriate gas cylinder into the sample loop). The program and data acquisition were then started. Figure 4.4 shows the chromatograms of standards injected to identify and quantify peaks in irradiated foam atmosphere, and Fig. 4.5 shows a chromatogram of the irradiated foam atmosphere under identical gas chromatographic conditions. Note that the plots have been Y-offset for clarity in both figures. 
Table 4.4. Gas chromatography program conditions

\begin{tabular}{cc}
\hline Parameter & Setpoint \\
\hline Initial temperature & $30^{\circ} \mathrm{C}$ \\
Initial delay & 5 minutes \\
Ramp rate & $10^{\circ} \mathrm{C} / \mathrm{min}$ \\
Final temperature & $150^{\circ} \mathrm{C}$ \\
Argon flow & $12 \mathrm{cc} / \mathrm{min}$ \\
\hline
\end{tabular}

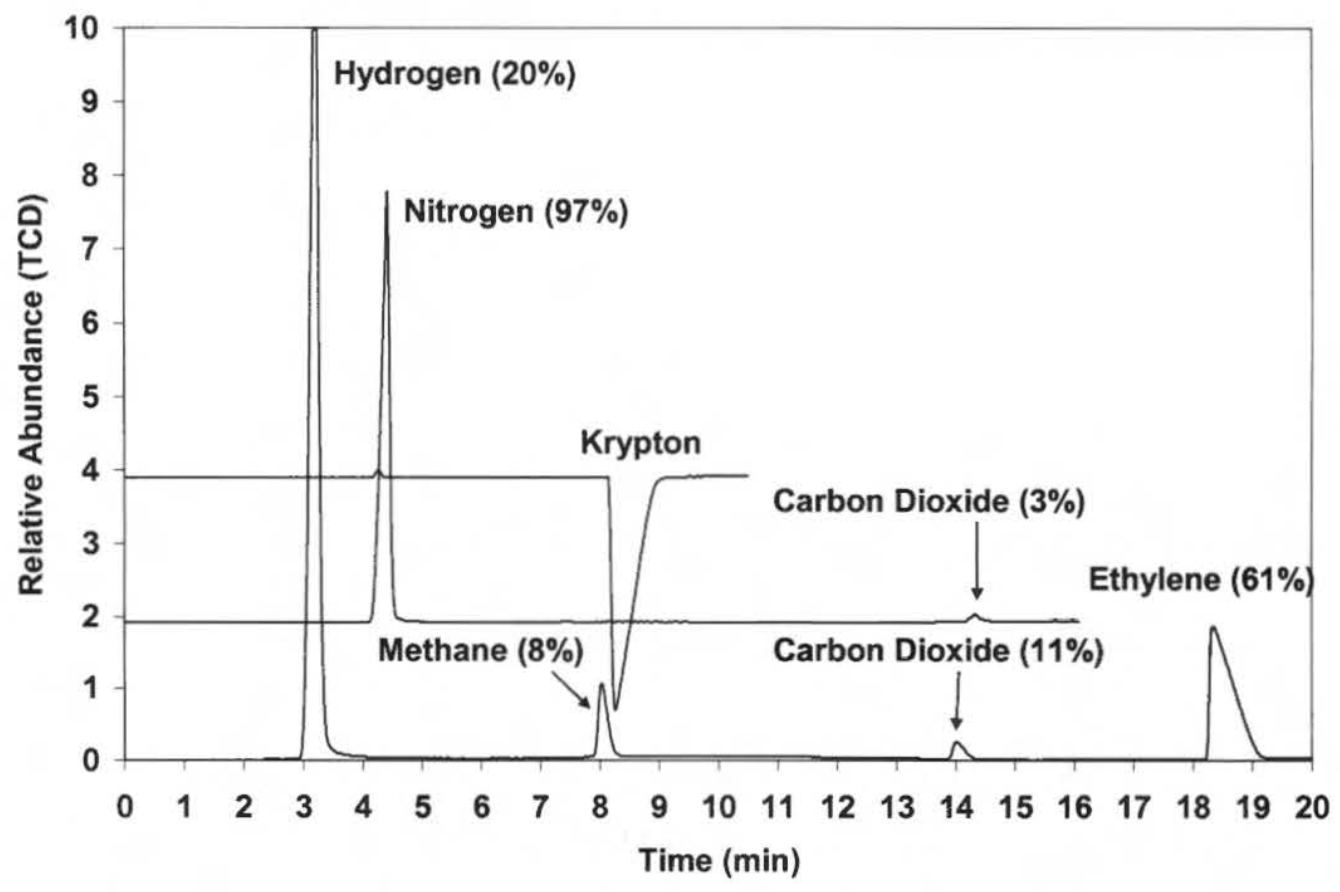

Fig. 4.4. Gas chromatograph of standards injected to identify and quantify peaks in irradiated foam atmosphere. 


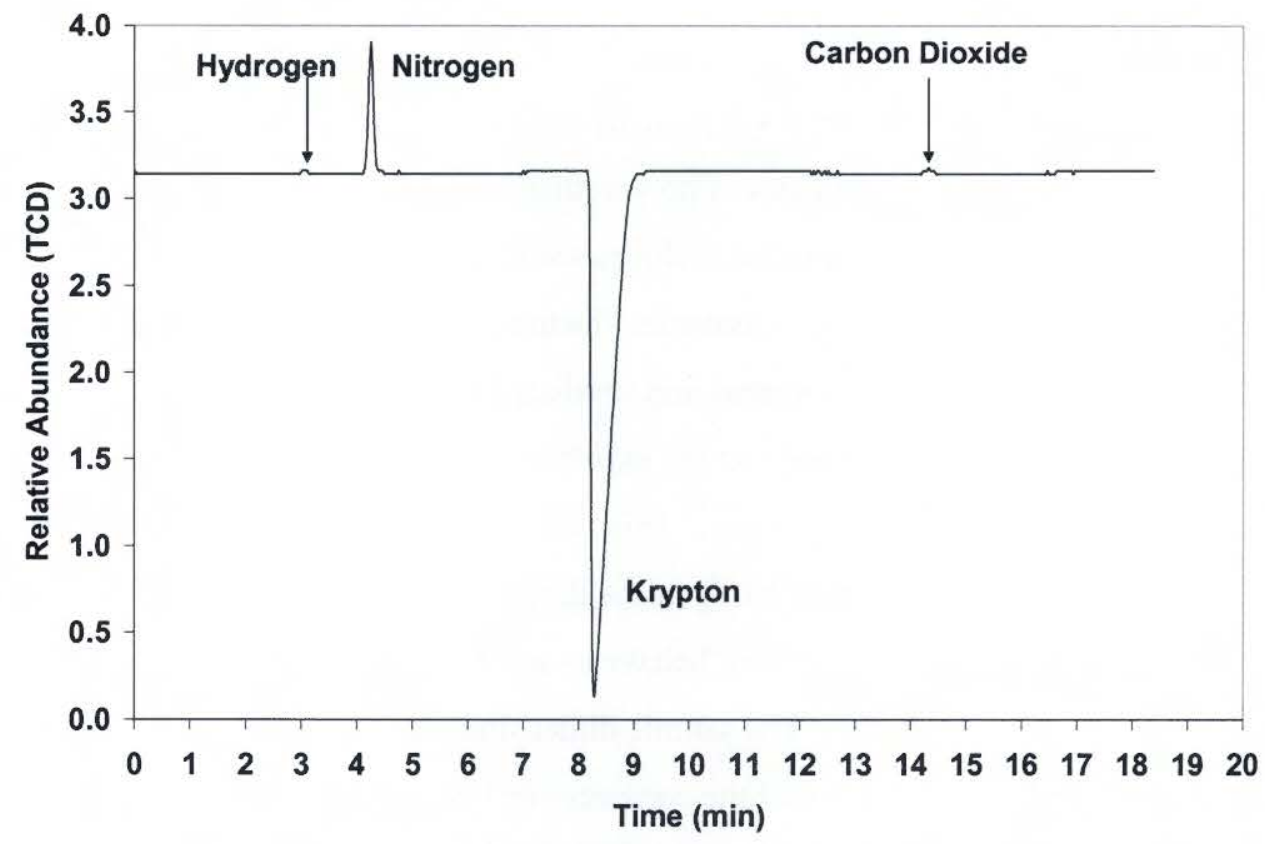

Fig. 4.5. Gas chromatograph of irradiated foam atmosphere.

Figures 4.4 and 4.5 show the presence of krypton, nitrogen, carbon dioxide, and hydrogen in the diluted foam atmosphere. Oxygen was not discernible, possibly because of its low concentration (Table 4.3), and water was not evident because of the chromatographic conditions.

By integration, the quantity of the krypton was determined to be $80.94 \%$ in the sample bag. This value was used to correct the calculated percentages from peak integration. Table 4.5 summarizes the results. The nitrogen was determined to be $53.97 \%$, in excellent agreement with the $52.66 \%$ calculated from the relative abundance data from the mass spectra work. The carbon dioxide was determined to be $8.36 \%$, slightly less than the $10.26 \%$ calculated from the mass spectra work. Note that hydrogen was present with a calculated value of $1.48 \%$. No other peaks were detected.

Table 4.5. Calculated air components in the irradiated foam atmosphere from the gas chromatography data

\begin{tabular}{cc}
\hline Air component & Percentage (\%) ${ }^{a}$ \\
\hline Nitrogen (\%) & 53.97 \\
Hydrogen (\%) & 1.48 \\
Carbon dioxide (\%) & 8.36 \\
\hline${ }^{a}$ Corrected for dilution by krypton.
\end{tabular}




\subsection{PYCNOMETRIC DETERMINATION OF DENSITIES AND POROSITIES}

An Ultrapycnometer 1000 manufactured by Quantachrome Corporation was used to determine the pycnometric densities and connected porosities of polyurethane samples before and after irradiation. Given the random nature of the polyurethane foam that includes some relatively large bubbles in the porous structure, the determinations of densities and porosities fluctuated somewhat from sample to sample. Several samples were cored from the unirradiated and irradiated specimens using a cork boring tool.

The pycnometric measurements are based on the expansion of ultrapure nitrogen gas between two calibrated chambers with and without the samples. This volume expansion is a function of the porosity present in the sample that can be reached by nitrogen gas during the equilibration time of a few minutes. The microporosity not accessible to nitrogen will behave as solid volume for this technique. The results of the measurements are shown in Table 4.6. The sample dimensions are the average of at least five determinations using a caliper and minimizing the compression of the foam. As shown in Table 4.6, there is essentially no difference between the unirradiated samples and a preliminary sample irradiated for 5 days. There is, however, a significant difference for the actual sample irradiated for 25 days. The microscopic analysis of the samples described in Sect. 4.5, both optical and SEM, show very little difference between irradiated and unirradiated samples. The apparent conclusion is that the radiation damage slightly increases the size of the microporous structure so as to make it more accessible to nitrogen. Of all the properties, the connected porosity appears to be the most sensitive to irradiation.

\subsection{COMPRESSIVE STRENGTH DETERMINATIONS}

The irradiated sample (3.5-in. diam., 4-in. long) and an "as-received" unirradiated one (3.5-in. diam and 4.5-in. long) were tested for unconfined compressive strength. The equipment used was an MTS 2-post load frame model 810 with an MTS 10 kip actuator connected to an MTS 407 servohydraulic controller. The data were acquired and the system controlled using a Nation Instruments DAQ (16-bit resolution for analog-to-digital conversion) and a LabView data acquisition program written in-house. The compression proceeded at a speed rate of $1 \mathrm{in} . /$ minute.

The plotted data for both samples are shown in Fig. 4.6. The initial sharp decrease corresponds to the compression-only region. It is followed by compression plus deformation, which is a function of the length of the sample. The value at the intersection of the two slopes corresponds to the compressive strength, that is the maximum proportional limit. 
Table 4.6. Results of pycnometric density measurements of irradiated and unirradiated urethane foam samples

\begin{tabular}{|c|c|c|c|c|c|c|c|c|}
\hline Sample & $\begin{array}{l}\text { Diameter } \\
{[\mathrm{cm}]}\end{array}$ & $\begin{array}{l}\text { Length } \\
{[\mathrm{cm}]}\end{array}$ & $\begin{array}{c}\text { Geometric } \\
\text { volume } \\
{[\mathrm{cm} 3]}\end{array}$ & Mass & $\begin{array}{l}\text { Bulk density } \\
{[\mathrm{g} / \mathrm{cm} 3]}\end{array}$ & $\begin{array}{c}\text { Pycnometric } \\
\text { density } \\
{[\mathrm{g} / \mathrm{cm} 3]}\end{array}$ & $\begin{array}{l}\text { Unconnected } \\
\text { volume }\left[\mathrm{cm}^{3}\right]\end{array}$ & $\begin{array}{c}\text { Connected } \\
\text { porosity } \\
\%\end{array}$ \\
\hline \multirow{4}{*}{ Unirradiated } & 1.14 & 5.64 & 23.0 & 1.281 & 0.0556 & 0.0661 & 19.4 & 15.9 \\
\hline & 1.13 & 5.63 & 22.4 & 1.151 & 0.0513 & 0.0617 & 18.7 & 16.9 \\
\hline & 1.13 & 6.18 & 24.8 & 1.296 & 0.0522 & 0.0620 & 20.9 & 15.8 \\
\hline & 1.97 & 6.92 & 21.2 & 0.952 & 0.0450 & 0.0551 & 17.3 & 18.2 \\
\hline \multirow{3}{*}{$\begin{array}{c}\text { Actual } \\
\text { sample } \\
\text { irradiated } \\
25 \text { days }\end{array}$} & 1.13 & 5.91 & 23.7 & 1.555 & 0.0656 & 0.1274 & 12.2 & 48.5 \\
\hline & 1.13 & 6.24 & 25.0 & 1.540 & 0.0615 & 0.1990 & 7.74 & 69.1 \\
\hline & 1.14 & 6.56 & 26.7 & 1.747 & 0.0654 & 0.0875 & 20.0 & 25.2 \\
\hline $\begin{array}{l}\text { Preliminary } \\
\text { sample } \\
\text { irradiated } \\
5 \text { days }\end{array}$ & 2.10 & 12.0 & 41.6 & 2.173 & 0.0522 & 0.0600 & 36.0 & 13.5 \\
\hline
\end{tabular}

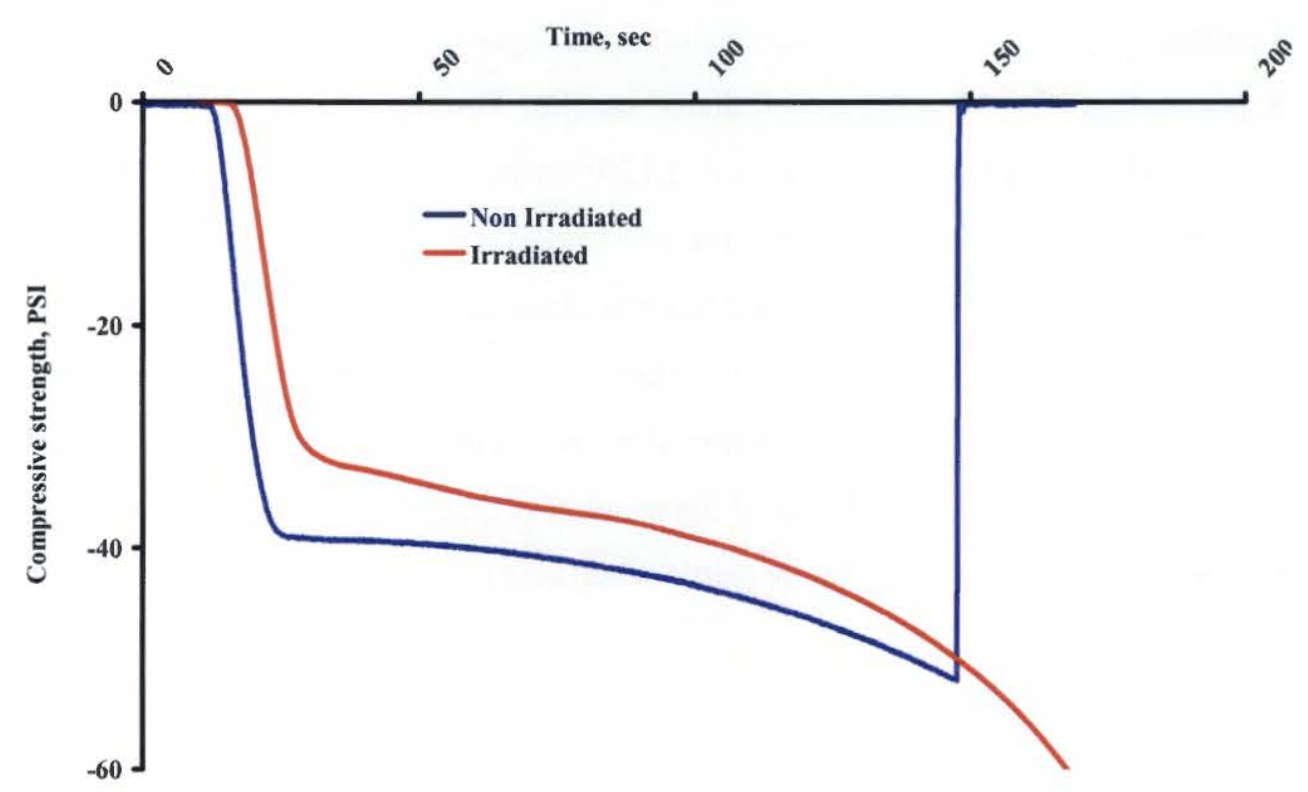

Fig. 4.6. Unconfined compressive strength for unirradiated and irradiated polyurethane foam samples. 
The resulting values for the compressive strength are 38.5 Psi for the unirradiated sample and 30.8 Psi for the irradiated sample. In other words, the compressive strength of the sample irradiated to a dose equivalent to more than 1000 years of alpha/gamma irradiation over the entire volume of the sample is about $80 \%$ of the original compressive strength.

\subsection{VISUAL AND MICROSCOPIC EXAMINATION OF UNIRRADIATED AND IRRADIATED SAMPLES}

As shown in Fig. 4.7, the irradiated sample is more yellow than the unirradiated one. Otherwise, there was no clear effect of irradiation on the bulk macro structure; however, it was noted that the irradiated sample was more brittle when being cut.

\subsubsection{Optical Microscopy}

Specimens from the irradiated and unirradiated polyurethane foam were both examined under an Olympus optical microscope with a Moticam2000 camera interfaced to a PC with Motic Images software. The camera contrast, brightness, and other parameters were adjusted when viewing the reference foam sample and kept constant when viewing the irradiated sample. Photographs of the flat top surface or exposed surface (irradiated sample) were obtained at $120 \times$ magnification for both samples (Figs. 4.8 and 4.9). Because of the random bubble pockets within the samples, comparison was difficult; but the irradiated sample appears to have more damaged foam pockets on the top surface.

The bulk material was then examined by cutting and pulling each sample in half. Figure 4.10 shows a typical photo of the bulk irradiated material. It is evident in this photo that the foam pockets appear not to be damaged and that there was no clear effect of the irradiation on the bulk macro structure; however, it was noted that the irradiated sample was more brittle when being cut. 


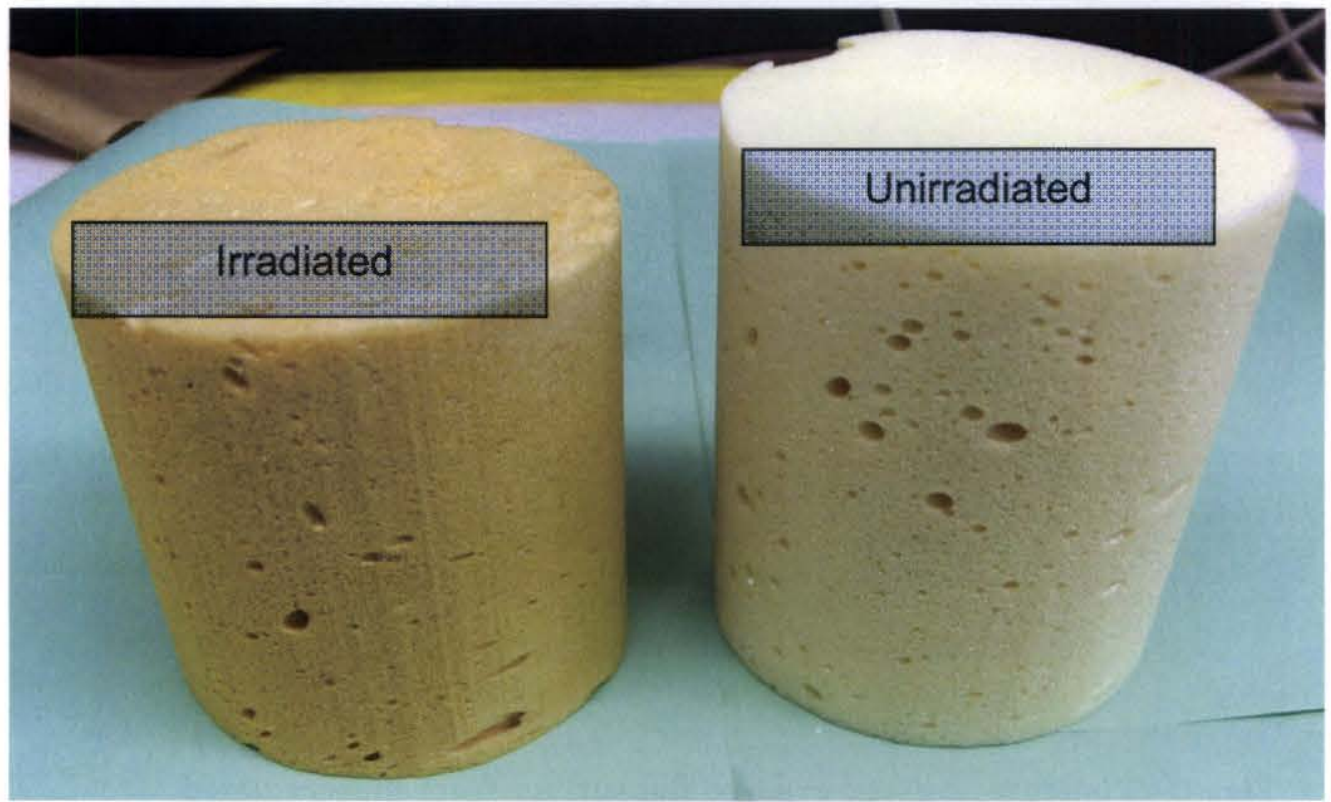

Fig. 4.7. Irradiated foam sample after removal from the test chamber beside an unirradiated specimen.

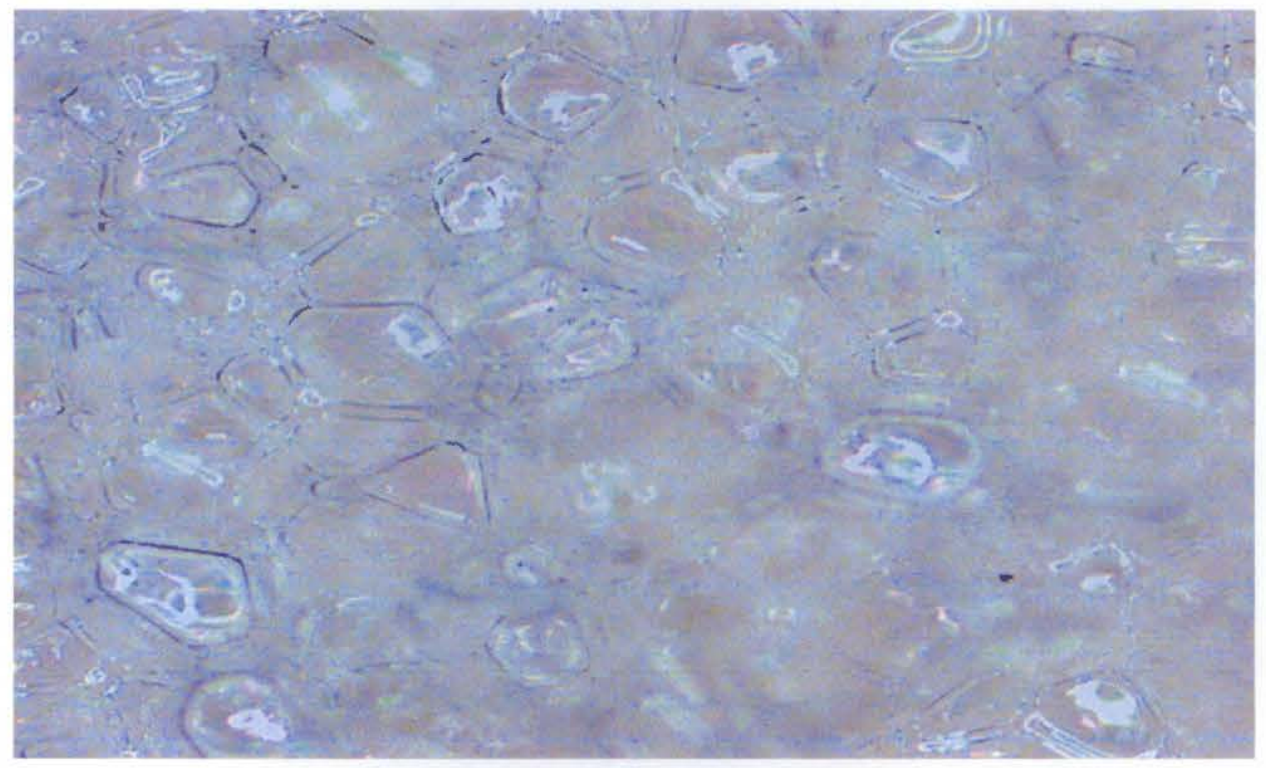

Fig. 4.8. Photograph of a unirradiated sample at $120 \times$ magnification. 


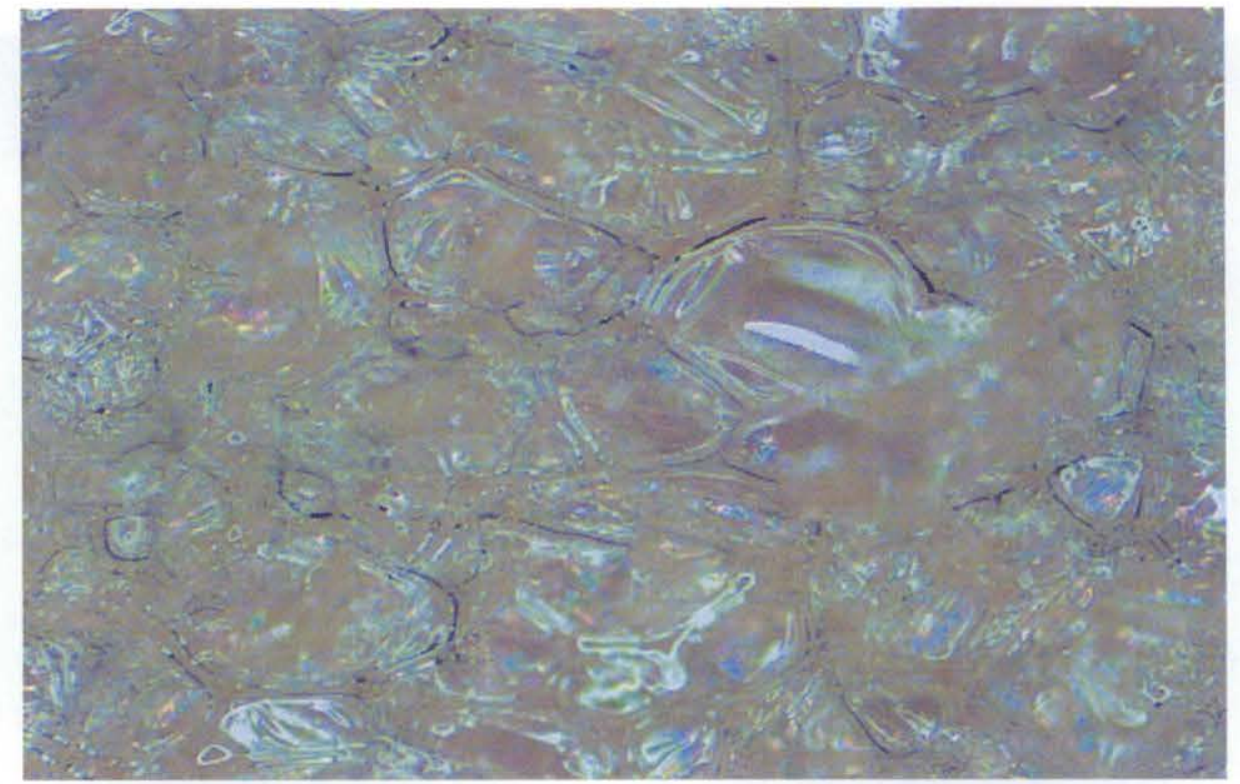

Fig. 4.9. Photograph of the exposed flat surface from the irradiated sample at $120 \times$ magnification.

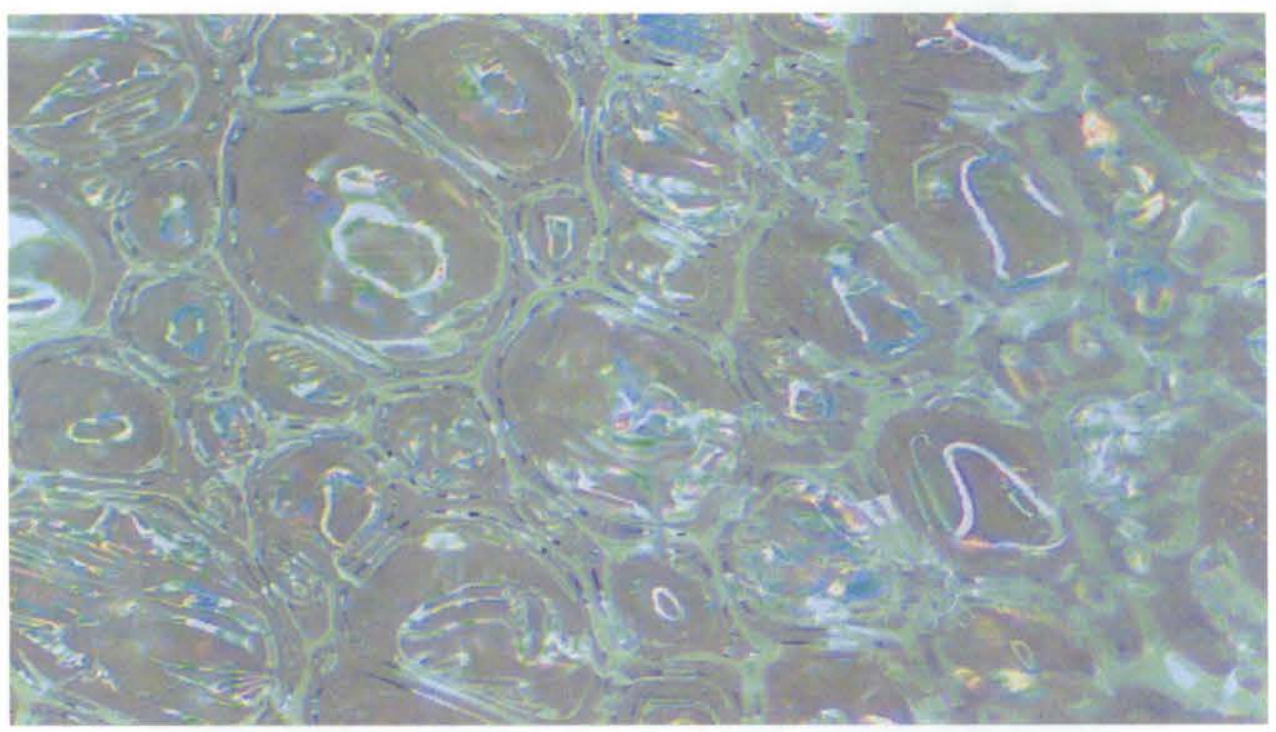

Fig. 4.10. Photograph of an internal section of the irradiated sample at $120 \times$ magnification. 


\subsubsection{Scanning Electron Microscopic Analysis of Irradiated and Unirradiated Samples}

SEM images were obtained by Dileep Singh of Argonne National Laboratory at three different locations for the irradiated (Fig. 4.11) and unirradiated samples (Fig. 4.12). All magnifications are 50×. In all cases, the foam cells are intact and no gross damage or differences are observed for the irradiated sample relative to the unirradiated one.
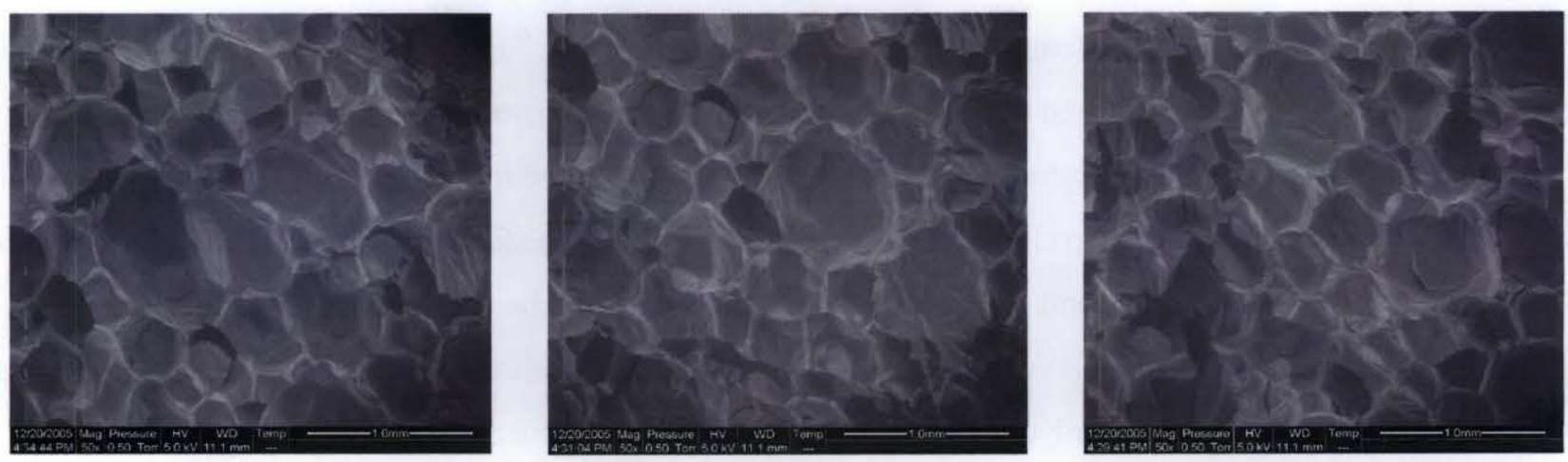

Fig. 4.11. Scanning electron microscopy images of the irradiated sample at $50 \times$.
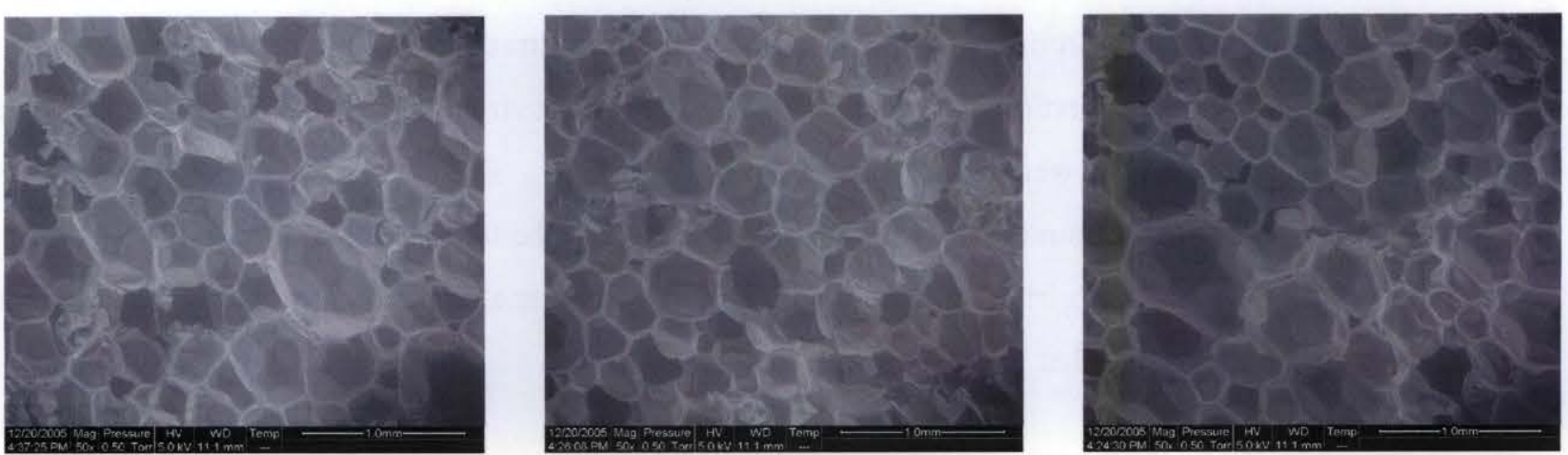

Fig. 4.12. Scanning electron microscopy images of the unirradiated sample at $50 \times$. 


\section{CONCLUSIONS}

To facilitate the dismantling and disposal of contaminated equipment, BJC is evaluating the possibility of filling the cavities of pipes and pieces using impervious urethane foam to restrict the mobility of the contaminants.

An irradiation and testing campaign was conducted to ascertain the stability and durability of the foam with respect to the radiation emitted by uranium that is expected to be present as a contaminant on the inner surfaces. It was assumed the maximum level of contamination expected was $2 \mathrm{~g}$ of ${ }^{235} \mathrm{U}$ distributed uniformly on the inner surface over an 18-in. length of 8 -in.-diam pipe.

Samples of the urethane foam were irradiated using the ORNL ${ }^{60} \mathrm{Co}$ irradiator to a dose equivalent to that expected to be accumulated in 1000 years for both alpha and gamma radiation from the uranium contamination. Most of the radiation dose from the uranium will be in the form of alpha particles reaching only the outer skin layer. Therefore, the surface of the polyurethane foam will absorb a much higher dose than the bulk of the sample, and most of the radiation damage will be confined to the surface.

The penetrating gamma rays from ${ }^{60} \mathrm{Co}$ will reach the entire volume of the foam sample. To evaluate the radiation damage to the polyurethane surface, the entire sample was irradiated at the higher level of exposure typical of the surface. Obviously, this was a very conservative approach and should give a significant degree of confidence regarding the radiation stability of the polyurethane foam.

Property measurements were performed on the urethane foam samples before and after irradiation. Additionally, gas generation from the foam was monitored during irradiation and the head-space gases analyzed at the end. The properties measured included compressive strength, density, and porosity. Visual and microscopic examination were employed.

The overall conclusion from the irradiation and testing is that the foam did not suffer any significant degradation during the gamma irradiation equivalent to a "1000-year alpha and gamma dose" on the entire volume of the specimen and that gas generation was minimal. 


\section{REFERENCES}

1. RADDECAY.EXE Radiation Decay Program, Grove Engineering, Inc., Rockville, Maryland, 1987.

2. Code of Federal Regulations, Vol. 49, Parts 100 to 185 ,. Transportation $\S 173.435$, Table of $\mathrm{A}_{1}$ and $\mathrm{A}_{2}$ values for radionuclides, p. 635, revised October 1, 2004.

3. L. C. Northcliffe. and R. F. Schilling, Range and Stopping Power Tables for Heavy Ions, Cyclotron Institute, Texas A\&M University, College Station, Texas, 1970.

4. A. S. Icenhour, Radiolytic Effects of Fluoride Impurities in a $U_{3} O_{8}$ Matrix, ORNL/TM-2000/157, Oak Ridge National Laboratory, Oak Ridge, Tennessee, May 2000.

5. G. Wagner, G., Evaluation of Decomposition Products in Polyurethane Foam after Irradiation, MCL report, December 2005 (draft).

6. R. M. Silverstein, F. X. Webster, and D. Kiemle, Spectrometric Identification of Organic Compounds, 7th Edition, Wiley, 2005. 
